
Yöntemlerle İncelenmesi

\author{
Tuncay Karakurt ${ }^{1}$ \\ ${ }^{1}$ Ahi Evran Üniversitesi, Mühendislik-Mimarlık Fakültesi, Kimya ve Proses Mühendisliği, 40100, Kırşehir, Türkiye \\ e-posta:tuncaykarakurt@gmail.com
}

Geliş Tarihi: 02.05.2018 ; Kabul Tarihi: 06.11.2018

Özet

Bu çalışmada, tiyadiazol halka içeren5-(2-kloro-6-florobenziltiyo)-1,3,4-tiyadiazol-2-amin tek kristali sentezlenmiştir. Sentezlenen kristalin yapısı, ${ }^{1} \mathrm{H}-\mathrm{NMR},{ }^{13} \mathrm{C}-\mathrm{NMR}$ ve $\mathrm{X}$-ışını analiz teknikleri ile aydınlatılmışır. Deneysel sonuçlara destek olması amacıyla da teorik hesaplamalar yapılmıştır. Bunun içinde bileşiğin geometrik parametreleri gaussian 09paket programı kullanılarak, yoğunluk fonksiyonel teorisi (DFT) B3LYP/6-31G(d) metodu ile optimize edildi ve yapısal parametreleri (bağ açıları, bağ uzunlukları ve dihedral açıları), ${ }^{1} \mathrm{H}$ - ve ${ }^{13} \mathrm{C}-\mathrm{NMR}$ spektrumları vesınır moleküler orbitalleri (HOMO-LUMO) teorik olarak hesaplanmıştır. Son olarak, sentezlenen tek kristalin inhibitör aktivite çalışması için, 2 WQY reseptör hedef yapısını inhibe etmek amacıyla moleküler doking simülasyonu yapılmıştır.

\title{
Investigation of The Crystal and Molecular Structure Of "5-(2-Chloro-6- Fluorobenzylthio)-1,3,4-Thiadiazol-2-Amine" Single Crystal Containing ThiadiazolRingby Experimental and Theoretical Methods
}

\begin{abstract}
In this work, a single crystal of 5-(2-chloro-6-fluorobenzylthio)-1,3,4-thiadiazol-2-aminecontaining thiadiazole ring was synthesized. The structure of the synthesized crystal was confirmed by ${ }^{1} \mathrm{H}-\mathrm{NMR}$,

Keywords

Thiadiazole; NMR;

DFT; HOMO-LUM;

Molecular Docking

${ }^{13} \mathrm{C}$-NMR and X-ray analysis techniques. Theoretical calculations have been made in order to support experimental results. In this, the geometric parameters of the compound were optimized by the density functional theory(DFT) B3LYP/6-31G(d) method using the gaussian 09 packet program and structural parameters (bond angles, bond lengths and dihedral angles), ${ }^{1} \mathrm{H}$ - and ${ }^{13} \mathrm{C}-\mathrm{NMR}$ spectra and frontier molecular orbitals (HOMO-LUMO) of the single crystal have been calculatedtheoretically. Finally, the molecular doking simulation was carried out to inhibit the 2 WQY receptor target structure for inhibitor activity study of the synthesized single crystal.
\end{abstract}

(c) Afyon Kocatepe Üniversitesi

\section{Giriş}

Son yıllarda çeşitli biyolojik aktivitelere sahip bileşiklerin sayısında önemli artışlar olmasına rağmen, bu bileşiklere karşı ilaç direncinin ortaya çıkması ve çeşitli yan etkilerinden dolayı kullanımları oldukça sınırlı kalmıştır. Bu yüzden kimyacılar, ilaç kimyasında kullanılacak biyolojik aktiviteye sahip bileşiklerin geliştirilmesi için büyük çaba harcamaktadır. Bu çalışmada, 1,3,4-tiyadiazol halkasını içeren 1,3,4-thiadiazol-2-amin türevinin sentezlenmesi, yapısının çeşitli spektroskopik yöntemlerle karakterize edilmesi ve bileşiğin antifungal aktivitesinin araştırılması amaçlandı.

İmidazol ve 1,3,4-tiyadiazol türevlerinin sentezi ve uygulamaları biyoaktif, sentetik ara geçiş ürünleri ve tıbbi ürünlerdeki etkilerinden dolayı oldukça dikkat çekmektedir. Mycobacterium tuberculosis bakterisinin yol açtığı tüberküloz hastalığının tedavisinde ve HIV enfeksiyonları için ilaç geliştirmede 1,3,4-tiyadiazol ve türevleri sıklıkla kullanılmaktadır (Tehranchian ve ark., 2005). 2Amino-1,3,4-tiyadiazol ve türevlerinin, yüksek 
derecede antikanser aktiviteye sahip olduğu bilinmektedir (Rollas, 1982). Ayrıca azot atomu içeren heterosiklik bileşiklerin sentezi için ara ürün olarak önemli bir kullanım alanı vardır. İmidazol ve 1,3,4-tiyadiazol türevlerinin; antimikrobiyal, antifungal,antibakteriyel,

antienflamatuar,antitüberküloz ve analjezik gibi birçok biyolojik aktivite göstermelerinden dolayı bu bileşiklerin ve türevlerinin sentezleri her geçen gün artmaktadır (Kim ve ark.,2013, Padmavath ve ark., 2011, Singh ve ark., 2016).Yine bu bileşikler, tarım alanında herbisit ve pestisit olarak kullanılmaktadır. Ayrıca bu bileşikler, koordinasyon kimyasında kullanışlı ligantlardır ve bugün hala bilimsel araştırmalarda önemli bir alan teşkil etmektedir (Fan ve ark., 2010). Bahsedilen bu biyolojik etkiler ışığında tiyadiazol türevi olan yeni tek kristal bileşiksentezlenmiştir. Bu sentezlenen tek kristalin yapısı, X-ışınları yapı analizi ve ${ }^{1} \mathrm{H}$ ve ${ }^{13} \mathrm{C}$-NMR spektral teknikleri kullanılarak aydınlatılmıştır. Deneysel çalışmalara destek olmak amacıyla teorik olarak NMR spektrumları ve sınır moleküler orbitalleri (HOMO-LUMO) incelenmiştir. Son olarak, sentezlenen tek kristalin, 2WQY reseptör hedef yapısı için inhibitör adayı olabilmesi amacıyla moleküler doking çalışmaları yapılmıştır.

\section{Materyal ve Metot}

\subsection{Kristalinsentezi}

5-(2-kloro-6-florobenziltiyo)-1,3,4-tiyadiazol-2-amin (KFT)Bileşiği daha önce sentezlenmiş (Wang ve ark., 2016) olup, bu çalışmada ise bileşiğin tek kristal sentezi aşağıdaki yönteme göre yapılmıştır.Yuvarlak tabanlı bir balona, 5-amino-1,3,4-tiyadiazol-2-tiyol (2) $(0.08 \mathrm{~mol})$ ve $\mathrm{KOH}(0.08 \mathrm{~mol})$ saf etanolde çözüldü. Çözelti, oda sıcaklığında yaklaşık 30 dakika karıştırıldı. 1-kloro-2- (klorometil) -3-florobenzen (0.08 mol) (1) safetanolde $(25 \mathrm{~mL})$ çözülerek bir damlatma hunisiyle bu çözeltiye oda sıcaklığında damla damla ilave edildi. Karışım 4-6 saat karıştırıldı. Reaksiyonun ilerlemesi, uygun zaman aralıklarında TLC ile izlendi. Reaksiyonun tamamlanmasından sonra karışım süzüldü ve elde edilen katı madde, sırasıyla saf su, etanol ve dietil eter ile yıkandı.Etanolden tekrar kristallendirilerek \% 84 verimle bileşik 3 elde edildi(Şekil 1).

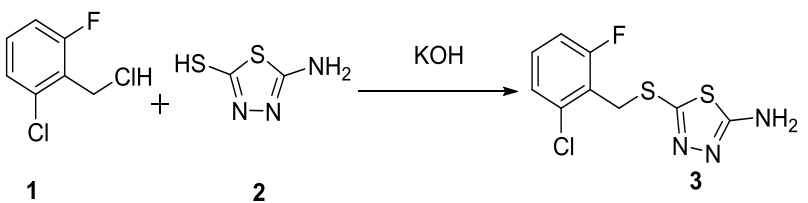

Kristalin X-ışını kırınım verileri, Bruker AXS APEX CCD (Bruker, 2008) difraktometresi ile MoKa ışını kullanılarak toplandı. SHELXT-2014 (Sheldrick, 2015a) programıyla direkt yöntemler Kullanılarak kristalin yapı çözümü elde edildi. Çözüm aşamasında hidrojen dışındaki atomların konumlarını tayin etmek için tam matris en küçük kareler yöntemini kullanan SHELXL-2014 (Sheldrick, 2015b) programı ile arıtım işlemi yapıldı. Arıtımın ilk safhasında atom konumlarının daha duyarlı hale gelmesi ve eksik atomların belirlenmesi için izotropik arıtım yapıldı. Arıtım sonucunda hidrojen atomları eklenmeden anizotropik arıtımyapılıp sonrasında hidrojen atomlarının konumları geometrik olarak belirlendi. Hidrojen atomları geometrik olarak yerleştirilirken aromatik $\mathrm{C}-\mathrm{H}$ bağ uzunlukları $0.93 \AA$, metilen $\mathrm{C}-\mathrm{H}_{2}$ bağ uzunlukları $0.97 \AA$ ve $\mathrm{NH}$ bağ uzunlukları ise $0.86 \AA$ olarak sabitlendi. Yapı çözümü ve arıtım için Olex2 (Dolomanov, 2009), moleküler çizimler için ise MERCURY (Macrae, 2008)programları kullanıldı.

\subsection{Teorik çalışmalar}

Tüm teorik hesaplamalar için, kuantum kimyasal hesaplama olan 6-31G(d) baz setli DFT(B3LYP) (Becke, 1993, Lee ve ark., 1998) teorisini kullanan gaussian 09 (frish ve ark., 2009) programı ve gaussian çıktılarını grafiksel olarak incelemek için de gausview 5 (Dennington ve ark., 2009) programı kullanıldı. Optimize işlemleri yapılan molekülün, moleküler doking çalışmaları da Autodock Vina (Trott ve Olson, 2010)programı kullanılarak yapıldı.Doking veri girişi dosyalarını oluşturmak için AutoDock Tools, Reseptör-ligant etkileşimleri göstermek için de Discovery Studio Visualizer 2017 (int Kyn. 1) yazılımları kullanıldı.

\section{Bulgular}

\subsection{Tek kristalin x-ışını yapı analizi ve moleküler geometrisi}

$\mathrm{C}_{9} \mathrm{H}_{7} \mathrm{ClFN}_{3} \mathrm{~S}_{2}$ kapalı formülüne sahip moleküle ait kristal parametreleri, veri toplama ve arıtım sürecindeki ayrıntılar Çizelge $1^{\prime}$ de, molekülün deneysel \%40 olasılıklı elipsoitlerle çizilmiş şekli Şekil 2-a, gaussian programı ile PES analizi sonucu ortaya çıkan konformasyonlardan elde edilen minimum enerjiye karşılık gelen molekül de Şekil 2b'de gösterilmiştir.

Şekil 1. Tiyadiazol tek kristalinin sentez prosedürü

\subsection{X-ışını çalış̧maları}




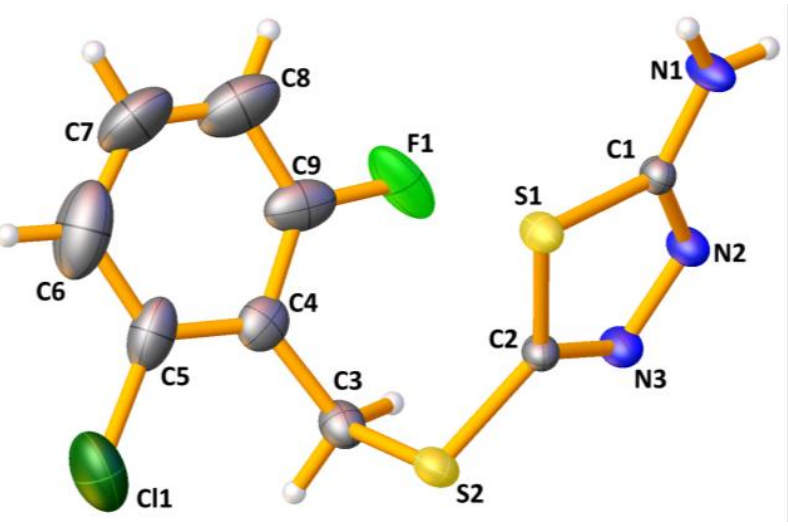

(a)

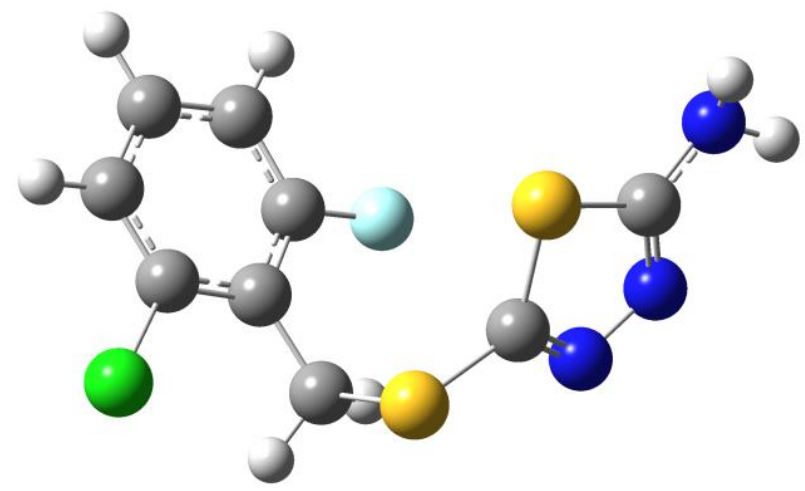

(b)

Şekil 2. $\mathrm{C}_{9} \mathrm{H}_{7} \mathrm{ClFN}_{3} \mathrm{~S}_{2}$ kapalı formülüne sahip tek kristalin(a) X-ışını ve (b) hesaplanan şekli

Çizelge 1. $\mathrm{C}_{9} \mathrm{H}_{7} \mathrm{ClFN}_{3} \mathrm{~S}_{2}$ kapalı formülüne sahiptek kristaline ait veri toplama ve arıtım değerleri

\begin{tabular}{|c|c|}
\hline Kimyasal Formül & $\mathrm{C}_{9} \mathrm{H}_{7} \mathrm{ClFN}_{3} \mathrm{~S}_{2}$ \\
\hline Molekül Ağırlığı & 275.75 \\
\hline Sıcaklık/K & $293(2)$ \\
\hline Kristal sistem & Monoklinik \\
\hline Uzay grubu & $\mathrm{C} 2 / \mathrm{c}$ \\
\hline $\mathrm{a} / \AA ̊ \AA$ & $36.801(7)$ \\
\hline $\mathrm{b} / \AA ̊ \AA$ & $6.1858(11)$ \\
\hline$c / \AA ̊$ & $10.2733(16)$ \\
\hline$\alpha /^{\circ}$ & 90 \\
\hline$\beta /^{\circ}$ & $102.853(6)$ \\
\hline$\gamma /{ }^{\circ}$ & 90 \\
\hline V/Å ${ }^{3}$ (Birim Hücrenin hacmi) & $2280.1(7)$ \\
\hline Z(Birim Hücredeki Molekül Sayısı) & 8 \\
\hline$D / g / \mathrm{cm}^{3}$ (Hesaplanan Yoğunluk) & 1.607 \\
\hline$\mu / \mathrm{mm}^{-1}($ çizgisel soğurma katsayısı) & 0.688 \\
\hline$F(000)$ & 1120 \\
\hline Kristal boyutu $/ \mathrm{mm}^{3}$ & $0.17 \times 0.11 \times 0.06$ \\
\hline Radyasyon & $\operatorname{MoK} \alpha(\lambda=0.71073)$ \\
\hline$\Theta$ aralığı/ ${ }^{\circ}$ & 6.684 to 56.802 \\
\hline İndeks Aralığı & $\begin{array}{l}-48 \leq h \leq 48,-8 \leq k \leq 8 \\
-13 \leq 1 \leq 12\end{array}$ \\
\hline Toplanan Yansıma & 22147 \\
\hline Bağımsız yansıma & $\begin{array}{l}2624\left[R_{\text {int }}=0.0587,\right. \\
\left.R_{\text {sigma }}=0.0324\right]\end{array}$ \\
\hline Parametre sayısı & $2624 / 0 / 145$ \\
\hline $\begin{array}{l}\text { Goodness-of-fit on } F^{2} \text { (Yerleşim } \\
\text { Doğrulama Faktörü) }\end{array}$ & 1.108 \\
\hline Sonuç R indeksi [l>=2 $\sigma(I)]$ & $\mathrm{R}_{1}=0.0843, w R_{2}=0.1826$ \\
\hline
\end{tabular}

Sonuç $R$ indeksi [Tüm data]

$\Delta \sigma_{\max }, \Delta \sigma_{\min }\left(\mathrm{e} / \AA^{3}\right)$

CCDC Numarası

Bileşik, birbirine neredeyse dik olan 2-kloro-6florobenzilve tiyadiazol halkalarına sahiptir. Deneysel ve teorik çalışmalardan elde edilen bağ uzunlukları, bağ açıları vedihedral açıları karşıllaştırmalı olarak Çizelge 2'de gösterilmiştir. Çizelge 2'de Kristalin X-ışını kırınımısonuçları incelendiğinde, N2=C1, N3=C2, N1-C1, S1-C1, ve S1C2 bağ uzunlukları sirasıyla,1.326(5),1.330(5),1.296(5), 1.746(4), ve 1.734(4) Å olup bu uzunluklar literatür değerleriyle, sırasıyla 1.308(3), 1.283(3), 1.345(3), 1.732(2) ve 1.734(2) Å ile uyum içerisindedir (Er ve ark., 2016). $\mathrm{Bu}$ bağ uzunlukları teorik olarak sırasıyla,1.312, $1.298,1.372,1.753$ ve $1.779 \AA$, literatürde ise, $1.306,1.296,1.373,1.764$ ve $1.774 \AA$ (Er ve ark., 2016) olarak hesaplanmıştır.X-ışını kırınımısonuçları ve teorik hesapların literatür değerleri ile uyum içinde olduğu görülmektedir. Kristalde moleküller arası iki adet $\mathrm{N}-\mathrm{H} . . . \mathrm{N}$ hidrojen bağı gözlenmiştir. Çözüm işlemi sonunda bulunan yapıya ait kristalin birim hücre içerisindeki paketlenme çizimi Şekil 3 'de, hidrojen bağlarına ait bilgiler ise Çizelge3'de verilmiştir.

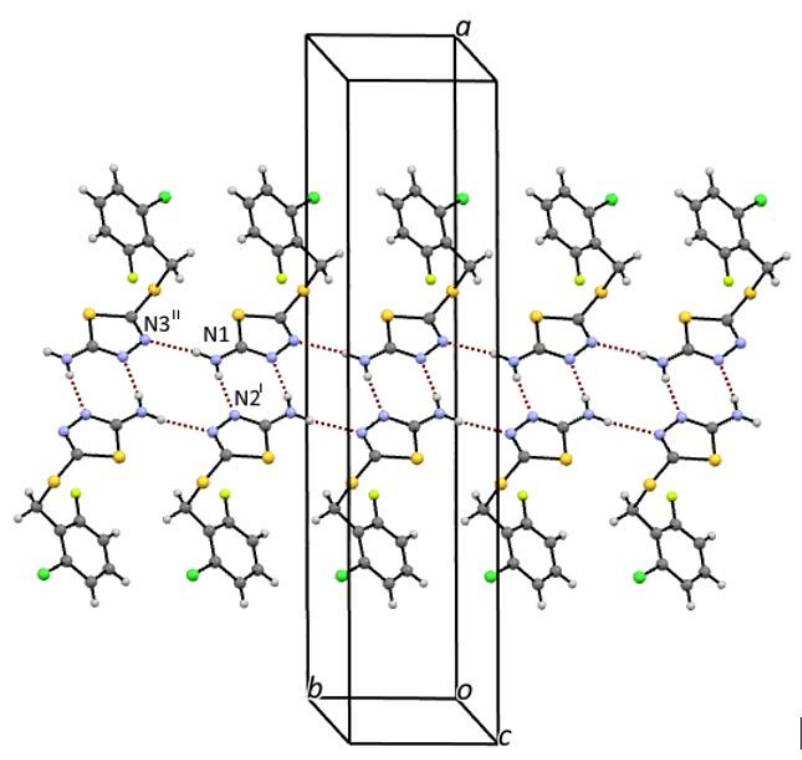

Şekil 3. $\mathrm{C}_{9} \mathrm{H}_{7} \mathrm{ClFN}_{3} \mathrm{~S}_{2}$ kapalı formülüne sahiptek kristalin $\mathrm{N}-\mathrm{H}$...N hidrojen bağları ile paketlenmiş gösterimi

Çizelge 2. $\mathrm{C}_{9} \mathrm{H}_{7} \mathrm{ClFN}_{3} \mathrm{~S}_{2}$ kapalı formülüne sahip tek kristaline ait deneysel ve teoriksel parametreler

\begin{tabular}{lll}
\hline Bağ Uzunlukları(Å) & Deneysel $\quad$ DFT B3LYP/6-31G(d)
\end{tabular} 


\begin{tabular}{|c|c|c|}
\hline S1-C1 & $1.746(4)$ & 1.753 \\
\hline S1-C2 & $1.734(4)$ & 1.779 \\
\hline $\mathrm{S} 2-\mathrm{C} 2$ & $1.751(4)$ & 1.765 \\
\hline S2-C3 & $1.834(5)$ & 1.867 \\
\hline $\mathrm{Cl} 1-\mathrm{C} 5$ & $1.692(8)$ & 1.759 \\
\hline F1-C9 & $1.316(8)$ & 1.084 \\
\hline N2-N3 & $1.360(5)$ & 1.363 \\
\hline $\mathrm{N} 2-\mathrm{C} 1$ & $1.326(5)$ & 1.312 \\
\hline N3-C2 & $1.296(5)$ & 1.298 \\
\hline N1-C1 & $1.330(5)$ & 1.372 \\
\hline C3-C4 & $1.476(7)$ & 1.500 \\
\hline C4-C9 & $1.419(9)$ & 1.400 \\
\hline $\mathrm{C} 4-\mathrm{C} 5$ & $1.387(8)$ & 1.404 \\
\hline $\mathrm{C} 9-\mathrm{C} 8$ & $1.359(10)$ & 1.387 \\
\hline $\mathrm{C} 5-\mathrm{C} 6$ & $1.444(12)$ & 1.394 \\
\hline $\mathrm{C} 7-\mathrm{C} 8$ & $1.315(13)$ & 1.393 \\
\hline C7-C6 & $1.395(14)$ & 1.394 \\
\hline \multicolumn{3}{|l|}{ Bağ Açıları () } \\
\hline $\mathrm{C} 2-\mathrm{S} 1-\mathrm{C} 1$ & $87.00(19)$ & 85.74 \\
\hline $\mathrm{C} 2-\mathrm{S} 2-\mathrm{C} 3$ & $99.1(2)$ & 100.52 \\
\hline C1-N2-N3 & $113.2(3)$ & 112.70 \\
\hline C2-N3-N2 & $113.4(3)$ & 114.25 \\
\hline N2-C1-S1 & $112.4(3)$ & 114.23 \\
\hline N2-C1-N1 & $123.6(4)$ & 122.57 \\
\hline N1-C1-S1 & $124.0(3)$ & 123.10 \\
\hline S1-C2-S2 & $123.2(2)$ & 122.18 \\
\hline N3-C2-S1 & $114.0(3)$ & 113.05 \\
\hline N3-C2-S2 & $122.7(3)$ & 124.76 \\
\hline C4-C3-S2 & $112.9(3)$ & 100.52 \\
\hline C5-C4-C3 & $124.7(6)$ & 124.11 \\
\hline $\mathrm{C} 5-\mathrm{C} 4-\mathrm{C9}$ & $115.2(6)$ & 115.63 \\
\hline F1-C9-C4 & $122.1(6)$ & 117.88 \\
\hline $\mathrm{Cl} 1-\mathrm{C} 5-\mathrm{C} 4$ & $112.5(7)$ & 119.61 \\
\hline \multicolumn{3}{|c|}{ Dihedral açılar $\left({ }^{\circ}\right)$} \\
\hline S2-C3-C4-C9 & $91.9(5)$ & 94.2 \\
\hline S2-C3-C4-C5 & $-86.4(6)$ & -85.7 \\
\hline $\mathrm{Cl} 1-\mathrm{C} 5-\mathrm{C} 6-\mathrm{C} 7$ & $178.8(6)$ & 179.7 \\
\hline F1-C9-C8-C7 & $178.8(7)$ & -179.7 \\
\hline N2-N3-C2-S1 & $-1.4(5)$ & 0.3 \\
\hline N2-N3-C2-S2 & $175.6(3)$ & -179.3 \\
\hline
\end{tabular}

Çizelge 3. $\mathrm{C}_{9} \mathrm{H}_{7} \mathrm{ClFN}_{3} \mathrm{~S}_{2}$ kapalı formülüne sahip tek kristalin Hidrojen Bağı Geometrisi $\left(\AA{ }^{\circ}{ }^{\circ}\right)$

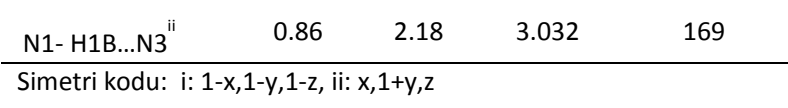

\subsection{NMR çalışmaları}

Moleküle ait deneysel ${ }^{1} \mathrm{H}$-NMR ve ${ }^{13} \mathrm{C}-\mathrm{NMR}$ spektrumları Şekil 4'de verilmiştir. Molekülün NMR kimyasal kayma değerlerini hesaplamak için GIAO (Gauge-Independent Atomic Orbital) (Ditchfield, 1972, Wolinski ve ark., 1990) yöntemi kullanılmış ve referans olarak TMS (tetrametilsilan) alınmıştır. TMS için dimetil sülfoksit (DMSO) çözücüsü seçilerek hesaplanan ${ }^{1} \mathrm{H}$-NMR ve ${ }^{13} \mathrm{C}$-NMR kimyasal kayma değerleri DFT/B3LYP/6-31G(d) için sırasıyla 32.10 ve 189.40 ppm'dir.Sentezlenen kristalin ${ }^{1} \mathrm{H}-$ NMR spektrumunda, metilen protonları $\left(-\mathrm{SCH}_{2}\right)$ kükürt atomunun elektronegatifliğinden dolayı biraz daha aşağı alanda (low field) 4.29 ppm'de bir singlet olarak gözlenmişolup, bu değer 3.60-3.98 ppm aralığında teorik olarak hesaplanmıştır. Aynı şekilde fenil halkasına ait iki adet proton sinyali 7.35 ve 7.21 ppm aralığında ölçülürken, bu sinyal değerleri, 6.48-7.02 ppm aralığında hesaplanmıştır. Tiyadiazol halkasına ait $\mathrm{NH}_{2}$ proton sinyali $7.40 \mathrm{ppm}$ değerinde ölçülmüştür.Bu sinyal değeri, 3.72-4.06 ppm aralığında teorik olarak hesaplanmıştır.Bileşin ${ }^{13} \mathrm{C}-\mathrm{NMR}$ spektrumunda ise, metilen grubu $\left(-\mathrm{SCH}_{2}\right)$ karbon pik sinyali, $\mathrm{sp}^{3}$ melezlenmiş karbonlardan beklendiği gibi ve kükürt atomunun elektronegatifliğinden dolayı 31.40 ppm'de kaydedildi. Teorik olarak ise bu pik sinyali 34.47 ppm olarak hesaplanmıştır. Diğer yandan fenil halkasında bulunan klor ve flor gibi elektronegatif atomlara komşu olan C5 ve C9 karbon pikleri 134.87 ve162.39 ppm olarak bu halkada en yüksek değerde ölçülmüştür. Son olarak tiyadiazol halkasına ve üç elektronegatif atoma komşu olan C1 ve C2 atomlarına ait pik değerleri de sırasıyla 171.71 ve 147.68 ppm ölçülmüştür. Deneysel ve hesaplanan diğer kimyasal kayma değerleri Çizelge 4'de gösterilmiştir
Çizelge 4. $\mathrm{C}_{9} \mathrm{H}_{7} \mathrm{ClFN}_{3} \mathrm{~S}_{2}$ kapalı formülüne sahip tek kristalin deneysel ve teorik ${ }^{13} \mathrm{C}-\mathrm{NMR}$ ve ${ }^{1} \mathrm{H}-\mathrm{NMR}$ kimyasal kayma değerleri

\begin{tabular}{lll}
\hline Atom (ppm) & Deneysel & DFT \\
\hline C1 & 171.71 & 160.64 \\
C2 & 147.68 & 148.08 \\
C3 & 31.40 & 34.47
\end{tabular}




\begin{tabular}{lll}
$\mathrm{C} 4$ & 126.12 & 113.25 \\
$\mathrm{C} 5$ & 134.87 & 129.30 \\
$\mathrm{C} 6$ & 123.58 & 112.23 \\
$\mathrm{C} 7$ & 130.90 & 116.29 \\
$\mathrm{C} 8$ & 115.16 & 101.82 \\
$\mathrm{C} 9$ & 162.39 & 148.20 \\
$\mathrm{H}(\mathrm{CH})$ & $7.35-7.21$ & $6.48-.7 .02$ \\
$\mathrm{H}\left(\mathrm{NH}_{2}\right)$ & 7.40 & $3.72-4.06$ \\
$\mathrm{H}\left(\mathrm{CH}_{2}\right)$ & 4.29 & $3.60-3.98$ \\
\hline
\end{tabular}

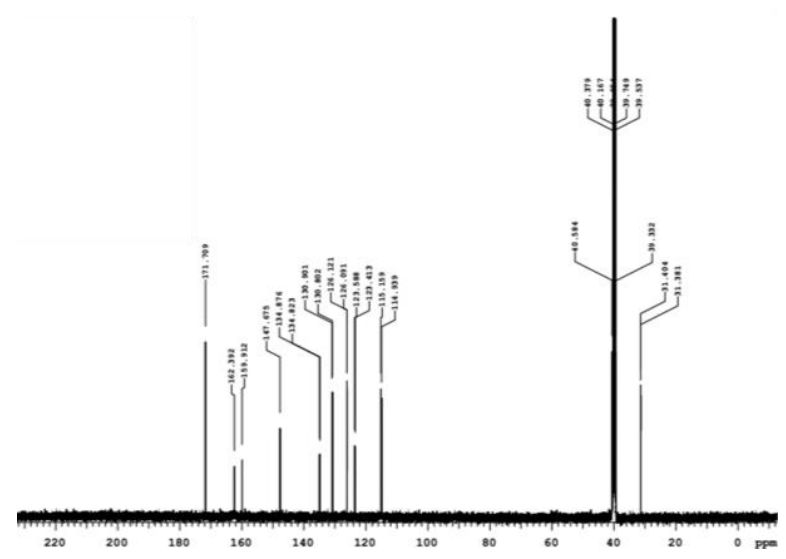

(a)

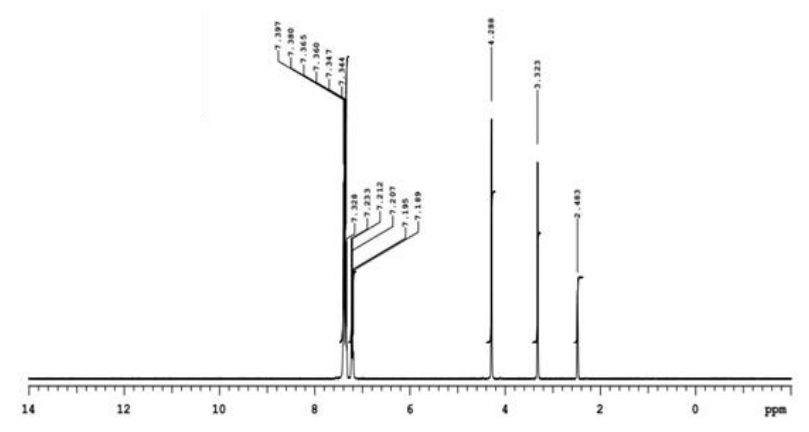

(b)

Şekil 4. $\mathrm{C}_{9} \mathrm{H}_{7} \mathrm{ClFN}_{3} \mathrm{~S}_{2}$ tek kristalinin deneysel (a) ${ }^{13} \mathrm{C}-\mathrm{NMR}$ (b) ${ }^{1} \mathrm{H}-\mathrm{NMR}$ spektrumları

\subsection{Frontier moleküler orbital analizi}

Bir moleküldeki en önemli orbitaller, sınır moleküler orbitaller olup HOMO ve LUMO olarak adlandırılır. Bu iki orbital arasındaki enerji farkı, molekülün kimyasal kararlılığının bir ölçüsü olup moleküler elektriksel taşıma özelliklerinin belirlenmesinde önemli bir rol oynar (Atkins, 1992). Hesaplanan HOMO enerjisi $-6.23 \mathrm{eV}$ ve LUMO enerjisi ise -1.22 eV'tur (Şekil 5). Bu enerji seviyeleri arasındaki fark ise ( $\triangle$ Eномо-цuмо) $-5.01 \mathrm{eV}$ olarak hesaplanmıştır.
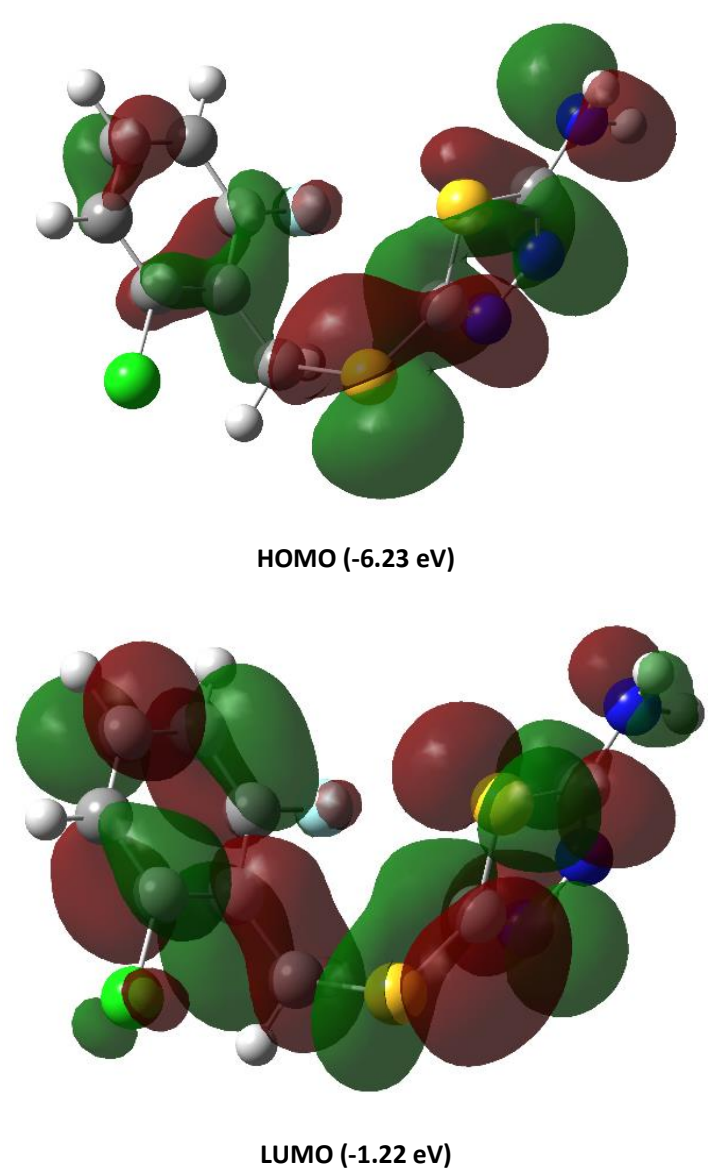

Şekil 5. Başıı bileşiğinin frontier orbitalleri ve enerjileri

\subsection{Moleküler doking çalışması}

Karboksamitlerilk sentezlenen sistemik fungisitlerdir. Özellikle bazı pas, sürme ve rastık hastalıklarına karşı, fungus hücrelerindeki mitokondriler üzerinde etkili olmaktadırlar. Solunumda önemli role sahip olan suksinik hidrogenazenziminin aktivitesini önleyerek etkili olurlar. Bu grupta karboksin maddesi önemli fungisitler arasında yer alır. Karboksin (KBS) tohum ilacı olarak, tahıllarda görülen sürme ve rastık hastalıklarıyla Rhizoctonia solani'nin neden olduğu çökerten hastalığına karşı kullanılmaktadır. Doking çalışmaları için KBSmolekülü içeren suksinik hidrogenaz enziminin kompleks yapısı (pdb code:2WQY), Protein Data Bank (http://www.rcsb.org/pdb) üzerinden sağlanmıştır. Doking işlemi öncesi 2WQY Protein yapısından su molekülleri kaldırılarak hidrojen atomları ve Gasteiger yükleri ilave edilmiştir. Bu işlemlerden sonra kullanılan KBS, KFT ve molekülden $\mathrm{Cl}$ ve Fatomları silinmiş KFT2ligantlarıyla hedef proteinin aktif bağlanma bölgelerine doking işlemleri yapılmıştır (Şekil 6). Moleküler doking sonucu tahmini bağlanma enerjisi (doking skoru) değerleri elde edilmiş sayısal sonuçlar ve tüm ligantların 
HOMO, LUMO enerjileri ve bu iki enerji seviyesi arasındaki farklar karşılaştırmalı olarak Çizelge5'de gösterilmiştir.

Çizelge 5. KBS, KFT ve KFT2ligantlarının farklı konformasyonlarına ait afinite ve HOMO, LUMO ve HOMO-LUMO enerji değerleri
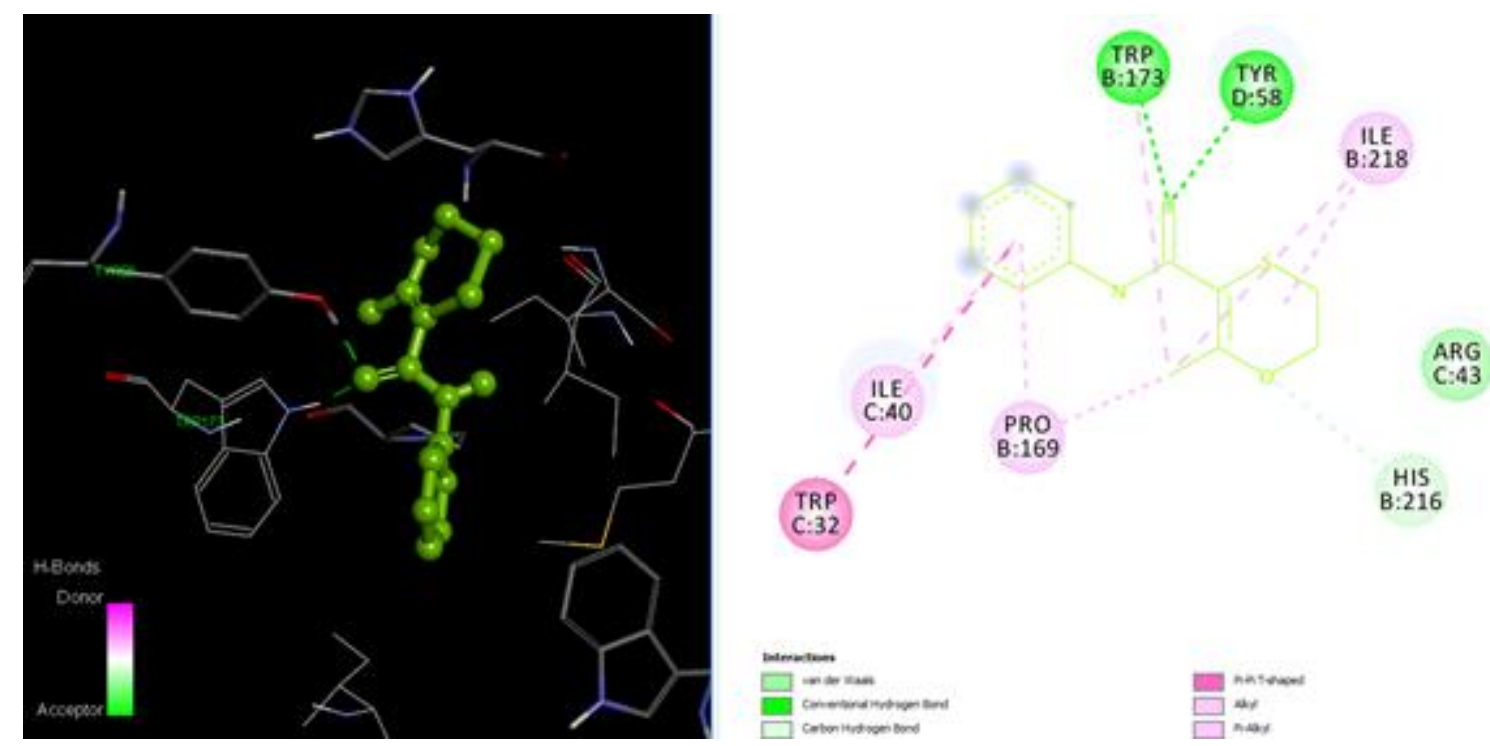

(a)
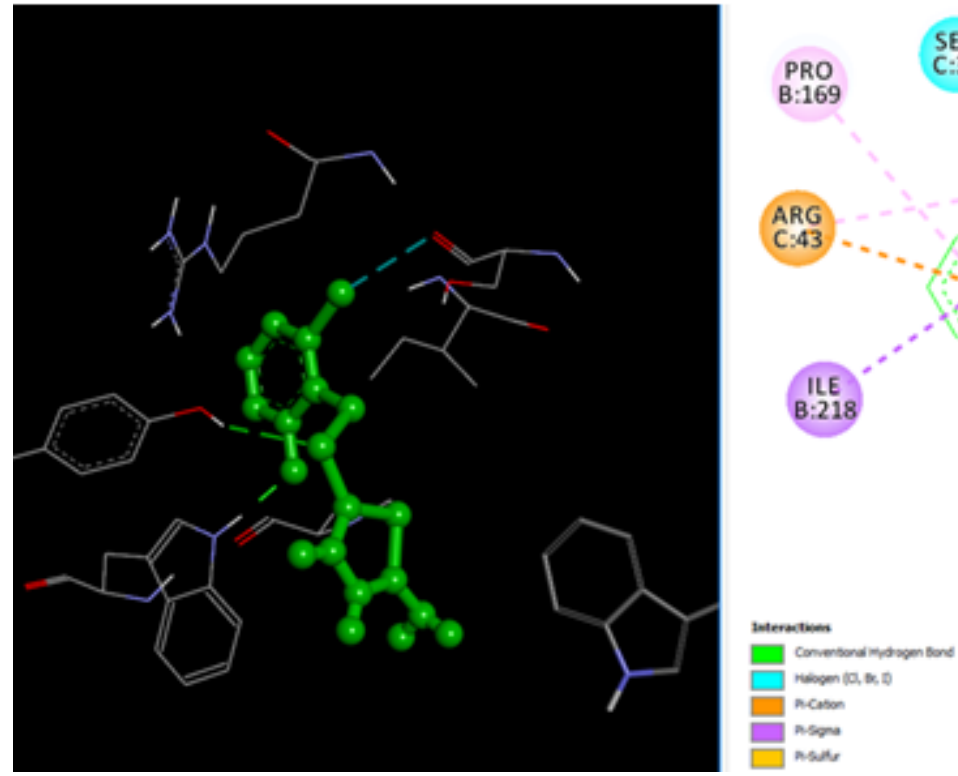

SER

B:169

\begin{tabular}{lllll}
\hline Ligant & $\begin{array}{l}\text { Afinite } \\
(\mathbf{k c a l} / \mathbf{m o l})\end{array}$ & $\begin{array}{l}\text { HOMO } \\
(\mathbf{e V})\end{array}$ & $\begin{array}{l}\text { LUMO } \\
\mathbf{( e V )}\end{array}$ & $\begin{array}{l}\boldsymbol{\Delta} \text { Eномо-Lumо } \\
(\mathbf{e V})\end{array}$ \\
\hline KBS & -6.6 & -5.59 & -0.75 & -4.84 \\
KFT & -6.3 & -6.23 & -1.22 & -5.01 \\
KFT2 & -6.0 & -5.83 & -0.51 & -5.32 \\
\hline
\end{tabular}

(b) 

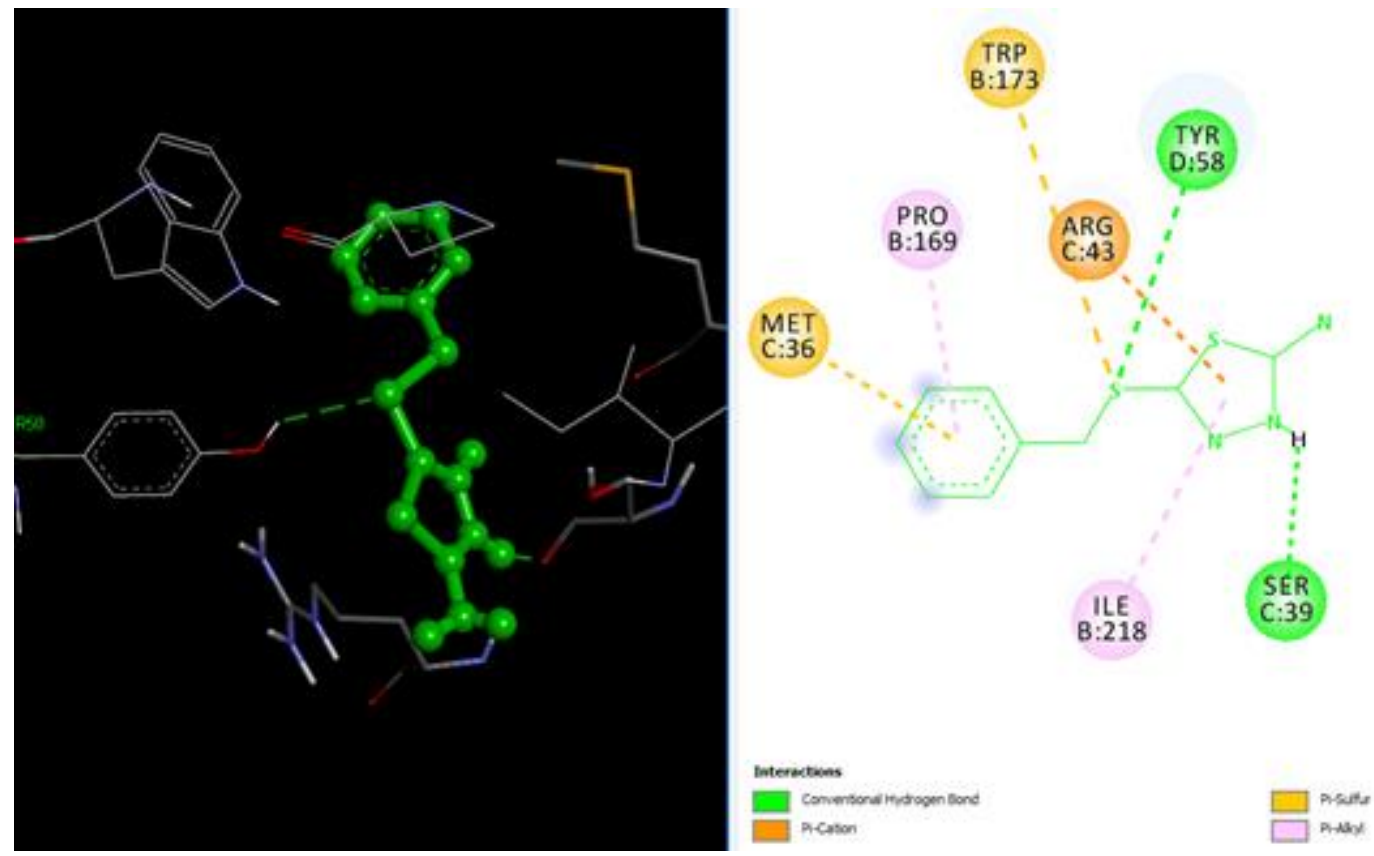

(c)

Şekil 6. (a)KBS (b)KFT ve (c)KFT2 ligantlarının doking sonucu reseptörün aktif bölgesi ile aralarındaki etkileşimlerinin 2D ve $3 \mathrm{D}$ gösterimi

Ligantların, reseptörlerin aktif bağlanma bölgelerine hidrojen bağı ve alkil grubu etkileşimleriyle bağlandığı görülmüştür. Şekil 6'da görüldüğü gibi reseptör ile referans KBS ligantının $O$ atomu ile TRP173 ve TYR58 aminoasitleri ile sırasıyla 1.91 ve $1.98 \AA$ uzunluğunda hidrojen bağları yapmaktadır. Aynı şekilde KFT ligantınında $S$ ve $\mathrm{F}$ atomları aynı aminoasitler ile sırasıyla 1.88 ve $2.81 \AA$ uzunluğunda hidrojen bağı etkileşimleri yaptığı görülmektedir. $\mathrm{Cl}$ ve $\mathrm{F}$ atomlarının bulunmadığı KFT2 ligantının $S$ atomu ile reseptörün TYR58 aminoasidi ile $2.93 \AA$ uzunluğunda bir hidrojen bağı yaptığı görülmektedir.Tüm diğeretkileşimler de Şekil 6'da gösterilmiştir. KFT ligantının, referans ligantının (KBS) reseptör ile yaptığı etkileşimlere benzer etkileşimler yaptığıŞekil $6^{\prime}$ da görülmektedir. Sonuç olarak, KFT ligantının, 2WQY hedef yapısı için inhibitör adayı olabilecek molekül olarak belirlenebileceği söylenebilir. Ayrıca Çizelge 4'de görüldüğü gibi HOMO-LUMO enerji farkı ile doking skoru ters orantılı olarak değişmiştir.

\section{Tartışma ve Sonuç}

$\mathrm{Bu}$ çalışmada, sentezlenen 5-(2-kloro-6florobenziltiyo)-1,3,4-tiyadiazol-2-amin tek kristalinin yapısı, X-ışınları kırınımı ve NMR spektroskopik yöntemleri ile aydınlatılmıştır. Ayrıca molekülün, teorik yöntemler kullanılarak moleküler yapısı ve NMR spektrumları belirlenmiş ve deneysel olarak elde edilen sonuçlarla karşılaştırması yapılmıştır. ${ }^{1} \mathrm{H}-\mathrm{NMR}$ spektrumunda tiyadiazol halkasına ait $\mathrm{NH}_{2}$ proton sinyali 7.40 ppmdeğerinde ölçülmüştür.2-amino-1,3,4 tiyadiazol türevleri $\mathrm{OH}$, $\mathrm{SH}$, amin $\mathrm{NH}_{2}$ gibi serbest proton içermemektedir. Bu yapılarda özellikle 2-amino-1,3,4 tiyadiazoldeki $\mathrm{NH}_{2}$ grubunda amin-imin tautomerik yapı söz konusudur. Bu nedenle yapıya azota bağlı azot asidik proton içermekte ve bu nedenle ${ }^{1} \mathrm{H}-\mathrm{NMR}$ spektrumunda $\mathrm{NH}$ protonu düşük alan yüksek ppm de çıkmaktadır. Bu durum literatürel verilerle (Sancak ve ark., 2007; Er ve ark., 2014, Er ve ark., 2016) desteklenmektedir. Teorik olarak yapılan hesaplamada bu pik 3.72-4.06 ppm aralı̆ı̆ında hesaplanmıştır. Literatürde bu pik 4.63 ppm(Mohamed va ark., 2017) ve 4.70 ppm (Shaaban ve ark., 2016) teorik olarak hesaplanmıştır. Bileşiğin kararlı yapısının ve yapısal parametrelerinin hesaplanmasından sonra, moleküler doking çalışmalarındaki aktivite üzerindeki etkisinden dolayı moleküle ait kararlı yapının HOMO ve LUMO enerji değerleri hesaplanmıştır. Çizelge $5^{\prime}$ de, düşük HOMO enerjisi olan KFT ligantının doking skoruKFT2'ye göre daha yüksek çıktığı görülmektedir. Literatürde de bu durum düşük homo enerjisine karşlık gelen ligantların biyolojik aktivitelerinin yüksek olduğu bildirilmiştir (Er ve ark., 2017). Son olarak molekül için mümkün bağlanma modelleri ve 
konformasyonlarını elde etmek için doking simülasyon işlemi yapılmıştır. Doking işlemi ile, moleküle $\mathrm{Cl}$ ve $\mathrm{F}$ atomları eklenmesi, reseptörün aktif bölgesi ile etkileşmelerin arttığı ve sentezlenen 5-(2-kloro-6-florobenziltiyo)-1,3,4tiyadiazol-2-amin bileşiğinin,2WQY protein yapısı için inhibitör adayı olabileceği gösterilmiştir.

\section{Kaynaklar}

Atkins P.W., 1992. The elements of physical chemistry (Oxford University Press Oxford United Kingdom).

Becke A.D., 1993. Density-functional thermochemistry. III. The role of exact exchange, The Journal of Chemical Physics, 98, 5648-52.

Bruker A., 2008. APEX2, V2008. 6, SADABS V2008/1, SAINT V7. 60A, SHELXTL V6. 14, Bruker AXS Inc., Madison, Wisconsin, USA.

Dennington R., Keith, T. and Millam, J., 2009. GaussView, version 5, Semichem Inc., Shawnee Mission, KS.

Ditchfield R., 1972. Molecular orbital theory of magnetic shielding and magnetic susceptibility, The Journal of Chemical Physics, 56, 5688-91.

Dolomanov O.V., Bourhis, L.J., Gildea, R.J., Howard, J.A. and Puschmann, H., 2009. OLEX2: a complete structure solution, refinement and analysis program, Journal of Applied Crystallography, 42, 339-41.

Er M., Işıldak G., Tahtaci H. and Karakurt T., 2016. Novel 2-amino-1,3,4-thiadiazoles and their acyl derivatives: Synthesis,structural characterization, molecular docking studies and comparison of experimental and computational results, Journal of Molecular Structure, 1110, 102-13.

Er M., Ergüven B., Tahtaci H., Onaran A., Karakurt T. and Ece A., 2017. Synthesis, characterization, preliminary SAR and molecular docking study of some novel substituted imidazo $[2,1-b][1,3,4]$ thiadiazole derivatives as antifungal agents, Medicinal Chemistry Research, 26, 615-30.
Er M., Şahin A. and Tahtaci H., 2014. Synthesis and characterization of novel 1,3-thiazole and 2-amino-1,3,4-thiadiazole derivatives, Macedonian Journal of Chemistry and Chemical Engineering, 33, 189-98.

Fan S.-H., Zhang, A.-G., Ju, C.-C., Gao, L.-H. and Wang, K.-Z., 2010. A Triphenylaminegrafted imidazo $[4,5-f][1,10]$ phenanthroline ruthenium (II) complex: Acid- base and photoelectric properties, Inorganic Chemistry, 49, 3752-63.

Frisch M., Trucks, G., Schlegel, H.B., Scuseria, G., Robb, M., Cheeseman, J., Scalmani, G., Barone, V., Mennucci, B. and Petersson, G., 2009. Gaussian 09, revision a. 02, gaussian, Inc., Wallingford, CT, 200.

Kim H.S., Jadhav, J.R., Jung, S.-J. and Kwak, J.H., 2013. Synthesis and antimicrobial activity of imidazole and pyridine appended cholestane-based conjugates, Bioorganic \& Medicinal Chemistry Letters, 23, 4315-18.

Lee C., Yang, W. and Parr, R.G., 1988. Development of the Colle-Salvetti correlation-energy formula into a functional of the electron density, Physical review B, 37, 785.

Macrae C.F., Bruno, I.J., Chisholm, J.A., Edgington, P.R., McCabe, P., Pidcock, E., RodriguezMonge, L., Taylor, R., Streek, J.V. and Wood, P.A., 2008. Mercury CSD 2.0-new features for the visualization and investigation of crystal structures, Journal of Applied Crystallography, 41, 466-70.

Mohamed T.A., Hassan A.E., Shaaban I.A., Abuelela A.M. and Zoghaib W.M., 2017. Conformational stability, spectral analysis (infrared, Raman and NMR) and DFT calculations of 2-Amino-5-(ethylthio)-1,3,4thiadiazole, Journal of Molecular Structure, 1130, 434-41.

Padmavathi V., Kumara C.P., Venkatesh B.C.and Padmaja A., 2011. Synthesis and antimicrobial activity of amido linked pyrrolyl and pyrazolyl-oxazoles, thiazoles and imidazoles, European Journal of Medicinal Chemistry, 46, 5317-26. 
Rollas S., 1981. Synthesis and spectrometric analysis of some 1, 2, 4-triazoline-5thiones, J Fac Pharm Istanbul, 17, 155-63.

Sancak K., Ünver Y. and Er M., 2007. Synthesis of 2Acylamino, 2-Aroylamino and Ethoxycarbonyl Imino-1,3,4-thiadiazoles as Antitumor Agents, Turkish Journal Chemistry, 31, 125-34.

Sheldrick G.M., 2015a. Crystal structure refinement with SHELXL, Acta Crystallographica Section C: Structural Chemistry, 71, 3-8.

Shaaban I.A., Hassan A.E., Abuelela A.M., Zoghaib W.M., and Mohamed T.A., 2016. Infrared, Raman and NMR spectral analysis, vibrational assignments, normal coordinate analysis, and quantum mechanical calculations of 2-Amino-5-ethyl-1,3,4thiadiazole, Journal of Molecular Structure, 1103, 70-81.

Sheldrick G.M., 2015b. SHELXT-Integrated spacegroup and crystal-structure determination, Acta Crystallographica Section A: Foundations and Advances, 71, 3-8.

Singh S.J., Rajamanickam, S., Gogoi, A., and Patel, B.K., 2016. Synthesis of 2-aminosubstituted-1, 3, 4-thiadiazoles via 2, 3dichloro-5, 6-dicyano-1, 4-benzoquinone (DDQ) mediated intramolecular C-S bond formation in thiosemicarbazones, Tetrahedron Letters, 57, 1044-47.

Tehranchian S., Akbarzadeh, T., Fazeli, M.R., Jamalifar, H., and Shafiee, A., 2005. Synthesis and antibacterial activity of 1-[1, 2, 4-triazol-3-yl] and 1-[1, 3, 4-thiadiazol-2yl]-3-methylthio-6, 7-dihydrobenzo [c] thiophen-4 (5H) ones, Bioorganic \& Medicinal Chemistry Letters, 15, 1023-25.

Trott O., and Olson, A.J., 2010. AutoDock Vina: improving the speed and accuracy of docking with a new scoring function, efficient optimization, and multithreading, Journal of Computational Chemistry, 31, 455-61.

Wang C., Song, H., Liu, W., and Xu, C., 2016. Design, synthesis and antifungal activity of novel thioureas containing 1, 3, 4-thiadiazole and thioether skeleton, Chemical Research in Chinese Universities, 32, 615-20.

Wolinski K., Hinton, J.F., and Pulay, P., 1990. Efficient implementation of the gaugeindependent atomic orbital method for NMR chemical shift calculations, Journal of the American Chemical Society, 112, 825160.

\section{internet kaynakları}

1- http://accelrys.com(07.12.2016) 